\title{
Providing critical care in ethical way. Traditions and ethics should go hand in hand
}

\author{
Abdus Salam Khan, Abdul Sattar, Hafsa Khan \\ Affiliation: Department of Emergency Medicine, Shifa International Hospital, H-8, Islamabad-44000, Pakistan. \\ Correspondence: Professor Abdus Salam Khan; E-mail: askhan90@gmail.com; Phone: +92 51846 4524; Mobile: +92 333 \\ 8882242.
}

\section{Abstract}

Ethics are at the core of healthcare provision. Good medical practice reflects ethics and professionalism in action and ethics should drive our behavior when providing medical care. The patients trust their treating doctor to be competent and ethical in their communication and also in the clinical decision-making. The expectations from the doctors are even more during the times when patients are critical. For the doctors and nurses providing the care, it may be very challenging, as those critical times are highly stressful for patients and attendants and can result in less than optimal outcome. Under these trying moments we face issues in communication and care provision which may look to be not conforming to the ethical standards. This editorial highlights the importance to adhere to the rules of ethics in many different critical situations, which may arise in emergency departments or in critical care units. But the principles outlined deserve to be learned by every healthcare staff member.

Key words: Critical Illness; Health Status; Humans; Intensive Care; Intensive Care Units; Critical Care / ethics; Decision Making / ethics; Dissent and Disputes; Physicians / ethics; Terminal Care / ethics

Citation: Khan AS, Sattar A, Khan H. Providing critical care in ethical way. Traditions and ethics should go hand in hand. Anaesth. pain intensive care 2020;24(6):582-585; DOI: 10.35975/apic.v24i6.1394

Received - 3 September 2020, Reviewed - 13 September 2020, Accepted - 31 October 2020

Good medical practice reflects ethics and professionalism in action and ethics should drive our behavior when providing medical care. ${ }^{1}$ In critical moments, doctors rely on information from patients and attendants and at the same time have to discuss highly sensitive topics with them. This situation leads on several occasions to either miscommunication or incomplete or imperfect decision making. ${ }^{2}$ Strict adherence to medical practice ethics will save us from such unfortunate situations.

Although the subject of 'ethics' is being taught at all levels, yet the treating physicians may have to struggle with issues revolving around ethics. One major factor is the cultural practices of our patients as well as unpreparedness of the system and doctors who are treating these patients. It may be hiding information from a sick patient or inappropriate exposure in the name of teaching, we come across practices, which either touch or at times cross the limits of ethical principles. In these circumstances, it may be difficult to provide good medical care, and be ethical as well as culturally sensitive. Such instances give us permanent uncomfortable memories. These dilemmas and instances have been studied extensively. ${ }^{3-5}$ The authors have picked those instances which mimic situations faced by our colleagues working with critical patients (Box 1).

What we have realized is that the end result is less influenced by the actions, rather by the attitudes of the people providing the care. ${ }^{6}$ This makes the case for the applied ethics to be practiced especially in circumstances where it is needed the most.

Traditionally ethics is founded on four basic principles; Autonomy, Beneficence, Non-maleficence 


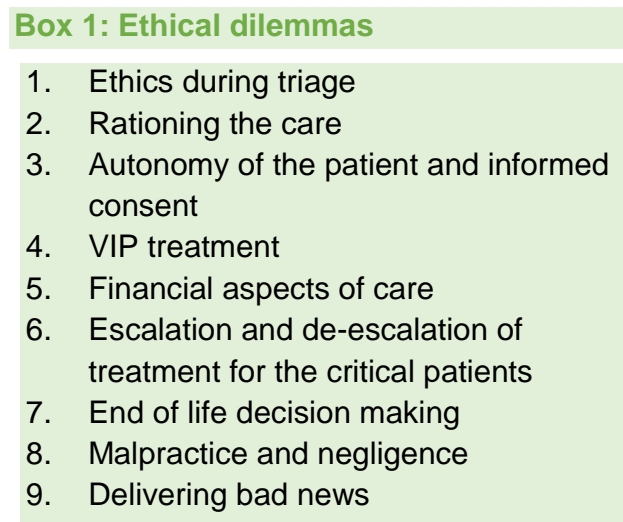

and Justice. During treatment phase of the critical patients we also need to keep other ethical aspects in our minds in order to avoid any conflict. These are all derived from these four principles and include Confidentiality, Informed consent, Disclosure and Dignity.

All these principles should be interpreted with local traditions and morals in mind, as they work within the boundaries of local tradition and morals. Most situations are complex and require complex decision making and may require a group of experienced doctors to handle these situations.

Let us look into the dynamics of these situations and ethical issues involved with potential solutions:

\section{Ethics during triage: ${ }^{7}$}

Triage of patients is all about managing the burden to balance it against the available resources. Availability of resources often brings the treating physicians at odds to choose between difficult choices. Letting patient wait may be necessary yet can be tricky and seen as delaying the treatment. Up-triaging or giving more resources to a mildly sick patient may be safer for him, yet it may deprive a more deserving patient from the limited resources. The best remedy to avoid delay in treatment or waste of resources due to poor triage practice is to have the most experienced nurse in triage as well as a robust system of re-triaging.

\section{Rationing the care: ${ }^{8}$}

The challenge of managing the patient burden versus the resources does not end at the triage but continues throughout the stay of the patient in the hospital. How do doctors and nurses match the resources to the number of patients presented to them is always complex. Bad outcomes are seen as negligence, whereas it is a more complex system issue, but it gets shoved onto the treating doctor or the nurse.

Incidents which are system based are not highlighted, as they tend to get politicized, shoved onto the weaker side, and the status quo continues. We need to identify the sickest and the problematic and do the regrouping or huddle. It must include the treating physicians and the nursing staff so that everybody is at the same page, and effectively deal with it. Both beneficence and nonmaleficence should be at work here.

\section{Autonomy of the patient and informed consent:}

The most challenging aspect of medical care is to provide patients with autonomy of decision-making. It is challenging because in plenty of circumstances, patient's family and attendants are seen doing the decision making while the patient is completely unaware of the diagnosis or the prognosis. The medical care provided within the emergency department or the critical care is usual very dynamic and complex, so it's a big challenge to brief the patient about the treatment and the sickness as well as involve them in the decision-making. Same thing goes regarding informed consent. The patient at times is the last person to know about the procedure which he/she is being subjected to.

It is hard to balance the family dynamics as well as to protect the patient and provide safe care. Should we disclose the information to the patient or treat while the patient is completely unaware? Disclosing will lead to a hostile family dynamic and a conflict with the treating team. Similarly, when the patients' exposure and education level put them at a disadvantage, then how to proceed? It is prudent to involve patient in the discussion of autonomy and document it with clear understanding of who will act as surrogate. This arrangement will help the team in complex decision making and be confident that it is ethically and morally sound.

\section{VIP treatment: 9}

Not just in Pakistan but throughout the world, when VIPs report to the critical care areas, there is always a degree of anxiety on the part of the managing team. There is a tendency to bypass the systems, directly involve the superiors, do lateral decision-making, and show signs of dissatisfaction. Treating team is always 
fearful of backlash, bad outcome, or complaints to the higher hierarchy, regardless of their full efforts. They try to cut the stay to as short as possible and expedite the care. A proper communication may become difficult or even impossible, as too many people are involved and the message gets lost.

Every situation is different yet ethical treatment entails that regardless of VIP status, we practice autonomy, confidentiality, beneficence and non-maleficence. Involving seniors, setting channels of communication directly with the patient, and frequent updates can be quite helpful and ethical ways to deal with this difficult situation.

\section{Financial aspects of care:}

Pakistan is a resource poor country and $75 \%$ of the healthcare cost comes from the patient's pocket. It's a big burden for most of the families. The more critical they are, the harder it is for them to bear the cost. Part of the treatment may be refused as it is seen as financially bearable by the family. The treating team may see it as a sign of mistrust. A conflict born.

The treating doctors and nurses need to understand the family dynamics quickly and try to work within the financial constraints. The more open and understanding we are regarding the financial aspects of the care, the better we can serve the patient and his needs.

\section{Escalation and de-escalation of treatment for the critical patients: 10}

It's a very distressing moment in the management of a critical patient when the decision is made to admit him to the intensive care or to step up the treatment, and the family is not able to understand the gravity of the situation. The decision might be seen as to be money driven. This situation gets even worse when the family is non-affording and you cannot find the appropriate place for the patient to be transferred to, leading to a dilemma of providing less than optimal care to the patient.

We must follow the principles of justice. Good communication with the patient and relatives is needed to have their trust in the system as well as the treating doctor and his team to make best decision for the patient. The patients need to be disclosed about the issues. The team should discuss about the probability of transferring the patient or creating appropriate resource and the decision made be conveyed to the patient and relatives to avoid the feeling of abandonment.

\section{End of life decision making:}

It is the most difficult time for the patient and/or the family. Most issues revolve around quality of care, resuscitation, financial burden, anxieties about death, pain and suffering, expected time of death and dignity of the patient during this process. Conflicting ideas float among the attendants, and clear understanding and decision-making is not seen.

It is difficult for the families to absorb the whole scenario and the situation is usually very charged and highly emotional. The best way to deal with it is to communicate with the family much early. The treating doctor needs to communicate the plan and discuss all those issues that can be the source of disagreement and hinder the decision making. Our traditional thinking and family system make it much harder to talk about end of life care and "do not resuscitate" decisions, yet good communication can always make patient and the attendants at ease.

\section{Malpractice and negligence:}

When patients are seen in the critical state, whether in the emergency department or the ICU, there is always an element of high anxiety and stress regarding the outcome. In all cases where outcome was less than optimal or beyond expectations of the family, the treating team is either considered as negligent or doing malpractice. The usual label is "too little, too late".

Involving senior doctors early, establishing good communication and appropriately timed disclosure to the family can avoid many misconceptions.

\section{Delivering bad news:}

Families of critically sick patients are already in turmoil and under stress, and disclosing any bad news in a casual way can lead to aggressive behavior, denial, accusation and confrontation. In an ongoing situation it is even more important to use best mode of communication to deliver bad news and win the cooperation of the family. The treating team needs to use best mode of communication by setting the scene, getting the background information, meet in a relaxed, congenial atmosphere, deliver the news in clear words, let the news sink in and finally be available for all 
questions and other help. We need to use ethics and deliver the bad news with dignity of patient in mind, and following rules of confidentiality to disclose as much as necessary, and in most humane and helpful way.

The need to stick to ethical practice in the times of stress and dealing with critical patients cannot be over stressed in areas of patient centered barrier, trust issues, lack of proper communication, and respect for the authority of the patient. ${ }^{11}$

In order to improve the ethical level of care, we must work to improve the overall system, in which the care process is designed to be safe for the patient, involves patient's family in communication and also has the senior faculty available to address any issue that can escalate. The staff should be taught about the importance of their work and that the patient should always occupy the center place in all that they do. They also need to improve and enhance their skillset and most importantly their communication skills. The more standardized the treatment would be, the less problems we shall face. Patients also need to be educated of their rights, as well as an expectation from them to cooperate with the treating staff and be respectful. All of these actions will bring trust into the relationship between the patients and the treating staff and result in less or no conflicts. ${ }^{2,6}$

Lastly, we would like to emphasize the need to practice ethics by all healthcare staff at all the levels of care. The physicians should be the advocates for the ethical practices and always help juniors learn the ethical principles in healthcare.

\section{Conflict of interest}

Nil declared by the authors

\section{Authors' contribution}

ASK - Concept, manuscript writing, review

AS - Research work, review, editing

HK - Review, editing

\section{References}

1. Markose A, Krishnan R, Ramesh M. Medical ethics. J Pharm Bioallied Sci. 2016 Oct;8(Suppl 1):S1-4. [PubMed] DOI: $\underline{10.4103 / 0975-7406.191934}$
2. Current Ethical Issues in Healthcare. Florida Tech Online. 2019 [cited 2020 Aug 18]. Available from: https://www.floridatechonline.com/blog/healthcaremanagement/current-ethical-issues-in-healthcare.

3. Page K. The four principles: Can they be measured and do they predict ethical decision making? BMC Med Ethics. 2012 May 20;13:10. [PubMed] DOI: 10.1186/1472-693913-10

4. Alkabba AF, Hussein GMA, Albar AA, Bahnassy AA, Qadi $M$. The major medical ethical challenges facing the public and healthcare providers in Saudi Arabia. J Fam Community Med. 2012;19(1):1-6. [PubMed] DOI: $\underline{10.4103 / 2230-8229.94003}$

5. House JB, Theyyunni N, Barnosky AR, Fuhrel-Forbis A, Seeyave DM, Ambs D, et al. Understanding ethical dilemmas in the emergency department: views from medical students' essays. J Emerg Med. 2015 Apr;48(4):492-498. [PubMed] DOI: 10.1016/j.jemermed.2014.09.058

6. Common Ethical Dilemmas for Doctors. Medscape. [cited 2020 Aug 29]. Available from: http://www.medscape.com/courses/section/898063

7. Aacharya RP, Gastmans C, Denier Y. Emergency department triage: an ethical analysis. BMC Emerg Med. 2011 Oct 7;11:16. [PubMed] DOI: 10.1186/1471-227X-11$\underline{16}$

8. Scheunemann LP, White DB. The ethics and reality of rationing in medicine. Chest. 2011 Dec;140(6):16251632. [PubMed] DOI: $10.1378 /$ chest.11-0622

9. Alfandre D, Clever S, Farber NJ, Hughes MT, Redstone $P$, Lehmann LS. Caring for 'Very Important Patients'-Ethical dilemmas and suggestions for practical management. Am J Med. 2016 Feb;129(2):143-147. [PubMed] DOI: 10.1016/j.amimed.2015.09.019

10. Oerlemans AJ, van Sluisveld $N$, van Leeuwen ES, Wollersheim H, Dekkers WJ, Zegers M. Ethical problems in intensive care unit admission and discharge decisions: a qualitative study among physicians and nurses in the Netherlands. BMC Med Ethics. 2015 Feb 26;16(1):9. [PubMed] DOI: 10.1186/s12910-015-0001-4

11. Robey T. Keeping Ethics Alive in the ED. Virtual Mentor. 2010 Jun 1;12(6):437-439. [PubMed] DOI: 10.1001/virtualmentor.2010.12.6.fred1-1006 m 